\title{
Screening of Rhizobacteria for their plant growth promotion abilities and their interaction with R hizobium of $\mathrm{M}$ ung bean
}

\author{
Shailesh J oshi* and A. Bohra \\ Microbiology Laboratory, Department of Botany, Jai Narain Vyas University, Jodhpur (Rajasthan), INDIA \\ *Corresponding author. E-mail: shailesh175@gmail.com
}

\begin{abstract}
Phosphorus deficiency is a major constraint for crop production. The beneficial microorganisms in the soil convert insoluble phosphorus into soluble form for plant growth and also prevents their leaching in to water bodies. In present investigation seventy two (72) rhizobacterial isolates were obtained from Mungbean rhizospheric soil on King's B medium, from various locations near Jodhpur. All the isolates were screened for their ability to solubilize insoluble phosphate on Pikovskaya's medium, nitrogen fixation and auxin like substance production. Four isolates were able to solubilize phosphate ranging from $42.69 \mu \mathrm{g} \mathrm{TCP} / \mathrm{ml}$ to $90.10 \mu \mathrm{g} \mathrm{TCP} / \mathrm{ml}$. Total fifty eight $(80.55 \%)$ isolates out of seventy two rhizobacteria were able to fix atmospheric nitrogen in vitro. Rhizobacterial isolates that were able to fix environmental nitrogen and solubilize phosphate were screened for auxin like substance production. Two isolates were able to produce auxin like substances at lower amount. Among all the rhizobacterial isolates screened for their influence on rhizobial growth in vitro, twenty three $(31.94 \%)$ isolates stimulated the growth of Mung bean Rhizobium. The diameter of zone of stimulation varied from $6.0 \mathrm{~mm}$ (MrbIV 14) to $16.5 \mathrm{~mm}$ (Mrbll 05 and Mrblll 16) and maximum stimulation was shown by Mrblll 10 (17.5 mm). However, thirty two (44.44\%) isolates were neutral to the growth of Mung bean Rhizobium.
\end{abstract}

Keywords: Mungbean, Rhizospherie, Rhizobium, Auxin, Phosphate

\section{INTRODUCTION}

Phosphorus deficiency is a major constraint for crop production. Plants absorb inorganic form of phosphorus which acts as an essential element for plant growth and development making up to $0.2 \%$ of plant dry weight. The level of phosphorus is very low in the soil and the available phosphorus is in insoluble form (Prasanna et al., 2011). The beneficial microorganisms in the soil convert insoluble phosphorus into soluble form for plant growth (Rodreguez and Fraga, 1999) by acidification, chelatioin and exchange reactions (Gerke, 1992) in the periplasm, which act as an indicator for routine isolation and selection procedures of phosphate solubilizing microorganisms (Illmer and Schinner, 1992). Bacteria are the predominant microorganisms that can solubilize phosphate compared to fungi and actinomyces (Yin, 1988). The aim of present study was to screen different Rhizobacteria for their plant growth promotion abilities and their interaction with Rhizobium of Mung Bean.

\section{MATERIALSAND METHODS}

Collection of soil samples: Soil samples were collected from various field areas near Jodhpur city, during mung bean growing season in the year 2006. The rhizospheric soil samples were collected by random sampling method, collecting three replicates from same field.

I solation of rhizobacterial isolates: Ten grams of rhizospheric soil was transferred to a $250 \mathrm{ml}$ flask, having $90 \mathrm{ml}$ of autoclaved water. Flask was shaken for $5 \mathrm{~min}$ on a rotary shaker for homogenization. This was then serially diluted and six fold to eight fold dilution were plated on King's B medium (20.0g/l Proteose peptone, $8.0 \mathrm{ml} / \mathrm{l}$ Glycerol, $1.5 \mathrm{~g} / 1 \mathrm{~K}_{2} \mathrm{HPO}_{4}, 1.5 \mathrm{~g} / 1 \mathrm{MgSO}_{4} .7 \mathrm{H}_{2} \mathrm{O}, 18 \mathrm{~g} / \mathrm{l}$ Agar $\mathrm{pH}$ 7.0 \pm 0.2 ) (King et al., 1954). Plates were incubated at $28{ }^{\circ} \mathrm{C}$ in an incubator for seven days. Different colonies were picked up as and when they appeared during the course of incubation. Isolates were given different accession number. The letter " $M$ " in the accession number stands for mungbean and "rb" stands for rhizobacteria, first digit in roman represents the sample and next digits represents isolate number.Three Mung bean Rhizobium (MR-I, MR-II and MR-III) were also isolated from root nodules as described by Fred et al., (1932) and were maintained on Yeast Extract Mannitol Agar (Vincent et al., 1970).

Screening of rhizobacterial isolates for phosphate solubilization: All the isolates were screened on Pikovskya medium ( $10.0 \mathrm{~g} / \mathrm{l}$ Glucose, $0.5 \mathrm{~g} / \mathrm{l}$ Yeast extract, $0.5 \mathrm{~g} / \mathrm{l}$ Ammonium Sulphate, $0.2 \mathrm{~g} / \mathrm{l} \mathrm{KCl}, 0.2 \mathrm{~g} / \mathrm{l} \mathrm{NaCl}, 0.1$ $\mathrm{g} / \mathrm{MgSO}{ }_{4} 7 \mathrm{H}_{2} \mathrm{O}, 5.0 \mathrm{~g} / \mathrm{l} \mathrm{TCP}, \mathrm{FeSO}_{4} 4 \mathrm{H}_{2} \mathrm{O} \& \mathrm{MnSO}_{4}$ in traces, $18.0 \mathrm{~g} / \mathrm{l}$ Agar, $\mathrm{pH}$ 7.0 \pm 0.2 ) for P-solubilization, isolates showing zone of clearance are considered as positive and subjected for estimation.

Phosphate solubilizing capacity of rhizobacterial isolates 
was determined using Pikovskaya's broth $(10.0 \mathrm{~g} / \mathrm{l}$ Glucose, $0.5 \mathrm{~g} / \mathrm{l}$ Yeast extract, $0.5 \mathrm{~g} / \mathrm{l}$ Ammonium Sulphate, $0.2 \mathrm{~g} / 1 \mathrm{KCl}, 0.2 \mathrm{~g} / \mathrm{l} \mathrm{NaCl}, 0.1 \mathrm{~g} / \mathrm{l} \mathrm{MgSO}_{4} .7 \mathrm{H}_{2} \mathrm{O}, 5.0 \mathrm{~g} / \mathrm{l} \mathrm{TCP}$, $\mathrm{FeSO}_{4} 4 \mathrm{H}_{2} \mathrm{O}$ and $\mathrm{MnSO}_{4}$ in traces, $\mathrm{pH} 7.0 \pm 0.2$ ) (Pikovskaya, 1948) containing tri-calcium phosphate (in soluble) as $\mathrm{P}$ source. Pikovskya broth, $50 \mathrm{ml}$ in each $150 \mathrm{ml}$ flask, was dispensed to each flask $250 \mathrm{mg}$ tri-calcium phosphate (TCP) was added the flasks were sterilized at $15 \mathrm{psi}$ for 30 minutes and were inoculated with $0.1 \mathrm{ml}$ of $24 \mathrm{~h}$ old culture suspension of the isolates. One uninoculated treatment was also included. The flasks were incubated at $28 \pm 2^{\circ} \mathrm{C}$ on a gyratory shaker. Three replicates were maintained for each isolates and flasks were incubated for 10 days for soluble phosphorus estimation. Also the change in $\mathrm{pH}$ of the medium was recorded using a digital $\mathrm{pH}$ meter.

Estimation of phosphate solubilizing capacity: Pikovskaya's broth was prepared and $50 \mathrm{ml}$ volume was dispensed in each $150 \mathrm{ml}$ flask. The flasks were sterilized at $15 \mathrm{psi}$ for $20 \mathrm{~min}$. and were inoculated with $24 \mathrm{hr}$ grown culture of selected isolates. Uninoculated flasks were served as control. Treatments were duplicated. The flasks were incubated at $28 \pm 2^{\circ} \mathrm{C}$ on a gyratory shaker for 10 days. After incubation soluble phosphate was estimated by following procedure (Jackson, 1967).

At the end of incubation each culture suspension was centrifuged at 15,000 rpm for $20 \mathrm{~min}$. and supernatant was decanted in separate conical flasks. One $\mathrm{ml}$ of supernatant was dispensed in to $50 \mathrm{ml}$ of volumetric flasks. Ten ml deionized water (MQW) was added to each flask followed by a swirl, one drop of p-nitrophenol was added as an indicator, to develop yellow colour. The $\mathrm{pH}$ of the solution was adjusted with $0.5 \mathrm{M} \mathrm{H}_{2} \mathrm{SO}_{4}$ and $1 \mathrm{~N}$ $\mathrm{NaOH}$. Development of colourless solution indicates that the correct $\mathrm{pH}$ is attained.

Eight ml of Murphy-Riley colour developing solution was added to each flask and volume was made up to $50 \mathrm{ml}$ with deionized water. Flasks were kept for $15 \mathrm{~min}$. for colour development. After 15 min. absorbance was read on a spectrophotometer at $712 \mathrm{~nm}$ wavelength. Standard curve was also prepared with $0,20,50,80,110$ and 140 $\mu \mathrm{g} / \mathrm{ml}$ concentrations of $\mathrm{KH}_{2} \mathrm{PO}_{4}$.

Nitrogen fixation: To evaluate nitrogen fixing ability of rhizobacterial isolates plates of nitrogen free Malate Medium (5.0g / $/ \mathrm{Malic}$ acid, $0.5 \mathrm{~g} / \mathrm{l} \mathrm{\textrm {K } _ { 2 }} \mathrm{HPO}_{4}, 0.2 \mathrm{~g} / \mathrm{l} \mathrm{NaCl}$, $0.1 \mathrm{~g} / \mathrm{l} \mathrm{MgSO} .7 \mathrm{H}_{2} \mathrm{O}, 4.0 \mathrm{~g} / \mathrm{KOH}, 0.05 \mathrm{~g} / 1 \mathrm{FeSO}_{4} 4 \mathrm{H}_{2} \mathrm{O}, 0.01$ $\mathrm{g} / \mathrm{l} \mathrm{CaCl}, 0.002 \mathrm{~g} / 1 \mathrm{NaMoO}_{4} .2 .0 \mathrm{ml}$ Bromothymol Blue ( $0.5 \%$ Alc.), $18.0 \mathrm{~g} / \mathrm{l}$ Agar, $\mathrm{pH} 6.3-7.3 \pm 0.2)$ were prepared and streaked with rhizobacterial isolates. The plates were incubated for 4 days at $28 \pm 2{ }^{\circ} \mathrm{C}$. isolates fixing nitrogen exhibited growth on the medium, changing the colour from green to blue.

A uxin/A uxin like substance production: The selected rhizobacteria were grown in $100 \mathrm{ml}$ TY broth $(5 \mathrm{~g} / \mathrm{l}$
Tryptone, $3 \mathrm{~g} / \mathrm{l}$ Yeast extract, $\mathrm{pH} 7.0 \pm 0.2$ ) in $250 \mathrm{ml}$ Erlenmeyer flask in a gyratory incubator at $28 \pm 2{ }^{\circ} \mathrm{C}$ for 4 days. Flasks were covered with black carbon paper. The culture suspension was centrifuged at 10,000 rpm for 10 minutes to remove bacterial cells. One $\mathrm{ml}$ of the supernatant was mixed with $2 \mathrm{ml}$ of the Salkowaski reagent ( $1 \mathrm{ml}$ of $0.5 \mathrm{M} \mathrm{FeCl}_{3}$ in $50 \mathrm{ml}$ of 35 percent $\mathrm{HClO}_{4}$ ) (Gordon and Weber, 1951) with continuous agitation and the reaction mixture was incubated in the dark for $30 \mathrm{~min}$. Development of pink colour confirmed the production of IAA/IAA like substances. Absorbance was read at 530 $\mathrm{nm}$ and compared with standard curve that was prepared with stock solution of IAA $1.0 \mathrm{mg} / \mathrm{ml}$ (i.e. $1000 \mu \mathrm{g} / \mathrm{ml}$ ) in $50 \%$ ethanol.

Interaction with rhizobium: Preparation of rhizobacterial culture: The King's medium B broth was prepared, dispensed to $10 \mathrm{ml}$ portions into conical flasks and plugged with cotton. The flasks were autoclaved at $15 \mathrm{psi}$ for $30 \mathrm{~min}$. After cooling, the flasks were inoculated with a loopful of each isolate separately and kept for 48 hr on a gyratory shaker.

Preparation of rhizobium broth culture: The YEMA broth $(1.0 \mathrm{~g} / 1$ Yeast extract, $10.0 \mathrm{~g} / 1$ Mannitol, $0.5 \mathrm{~g} / 1$ $\left.\mathrm{K}_{2} \mathrm{HPO}_{4} 0.1 \mathrm{~g} / \mathrm{l} \mathrm{MgSO} \mathrm{Mg}_{4} .7 \mathrm{H}_{2} \mathrm{O}, 0.2 \mathrm{~g} / \mathrm{l} \mathrm{NaCl}, \mathrm{pH} 6.8\right)$ as prepared, dispensing $100 \mathrm{ml}$ portion into $250 \mathrm{ml}$ conical flasks and sterilizing it as above. One loopful of each isolates of Rhizobium was inoculated into the flask separately. The flasks were shaken on gyratory shaker for 5 days.

Preparation for interaction: Mung bean Rhizobium, was seeded into molten modified succinate medium $(10.0 \mathrm{~g} / \mathrm{l}$ Mannitol, $0.5 \mathrm{~g} / \mathrm{l}$ Yeast extract, $1.0 \mathrm{~g} / \mathrm{l}$ Sodium glutamate, $5.0 \mathrm{~g} / \mathrm{l}$ Sodium succinate, $0.01 \mathrm{~g} / 1\left(\mathrm{NH}_{4}\right)_{2} \mathrm{SO}_{4}, 0.5 \mathrm{~g} / 1$ $\mathrm{K}_{2} \mathrm{HPO}_{4}, 0.2 \mathrm{~g} / \mathrm{l} \mathrm{MgSO}{ }_{4} 7 \mathrm{H}_{2} \mathrm{O}, 0.1 \mathrm{~g} / \mathrm{l} \mathrm{NaCl}, 18.0 \mathrm{~g} / \mathrm{l} \mathrm{Agar}$, $\mathrm{pH} 6.8)$ at $45^{\circ} \mathrm{C}$ and plated, sterilized filter paper discs (5 mm diameter) impregnated into King's B culture broth of different rhizobacteria were placed in the seeded plates experiment was duplicated (Schwinghamer, 1971).

\section{Effect on seedling emergence}

Surface ster ilization of seeds: Seeds were sterilized with $0.1 \% \mathrm{HgCl}_{2}$, solution for $3 \mathrm{~min}$. respectively and there after washed 8 times with autoclaved distilled water.

Seed bacterization: Rhizobacterial isolates were grown in King's B broth for $48 \mathrm{hr}$. for seed bacterization the sterilized seeds were kept overnight in rhizobacterial culture and the control seeds were kept in sterilized broth. After incubation seeds were placed on water agar plates $(0.7 \%)$ aseptically (Parmar and Dadarwal, 1997). Plates were incubated at $37^{\circ} \mathrm{C}$ and after germination of seeds plates were kept at $28^{\circ} \mathrm{C}$. Observations were taken after 5 days after incubation.

\section{RESULTS}

P solubilization: All the isolated strains were screened 
for P-solubilization on Pikovskaya's medium. The medium contained tricalcium phosphate (TCP) as sole source of phosphate, which is insoluble in water. It was observed that MrbIII 7 has shown the largest zone of solubilization and MrbI 12 has shown the smallest zone of solubilization. However, isolate MrbIII 7 and MrbI 4 spread_considerably along the zone of solubilization, thus creating a larger zone of clearance.

When amount of phosphate solubilized in vitro was estimated it was observed that maximum amount of phosphate was solubilized by MrbII 9 (Fig. 1). However all the isolates decresed $\mathrm{pH}$ of the medium.

Nitrogen fixation: Total fifty eight (80.55\%) isolates out of seventy two rhizobacteria were able to fix atmospheric nitrogen in vitro. The sample wise distribution indicated that 15 isolates $(83.33 \%$ ) out of 18 isolates from sample I, 15 isolates $(93.75 \%$ ) out of 16 isolates from sample II, 15 (78.94\%) isolates out of 19 isolates from sample III and thirteen isolates (68.42\%) out of 19 isolates from sample IV were able to fix Nitrogen in vitro.
A uxin/ auxin like substance production: All the phosphate solubilizing isolates were screened for Auxin / Auxin like substances production. Two isolates MrbI 10 and MrbI 12 were able to produce Auxin / Auxin like compounds $7.3 \mu \mathrm{g} / \mathrm{ml}$ and $5.2 \mu \mathrm{g} / \mathrm{ml}$. (Fig. 2).

Interaction with rhizobium: Seventeen (23.61\%) isolates of Mung bean rhizobacteria were inhibitory to mung bean rhizobium. The diameter of zone of inhibition formed by different rhizobacterial isolates varied from 9.5 to 22.7 $\mathrm{mm}$ and isolate MrbI 18 showed maximum inhibition (25.6 $\mathrm{mm}$ ) while isolate MrbII 07 showed least inhibition (9.5 $\mathrm{mm})$.

Out of seventy two rhizobacterial isolates twenty three (31.94\%) isolates have stimulated the growth of Mung bean Rhizobium. The diameter of zone of stimulation varied from $6.0 \mathrm{~mm}$ (MrbIV 14) to $16.5 \mathrm{~mm}$ (MrbII 05 and MrbIII 16) and maximum stimulation was shown by MrbIII $10(17.5 \mathrm{~mm})$. However thirty two $(44.44 \%)$ isolates were neutral to the growth of Mung bean Rhizobium.

E ffect on seedling emergence: Seeds were inoculated

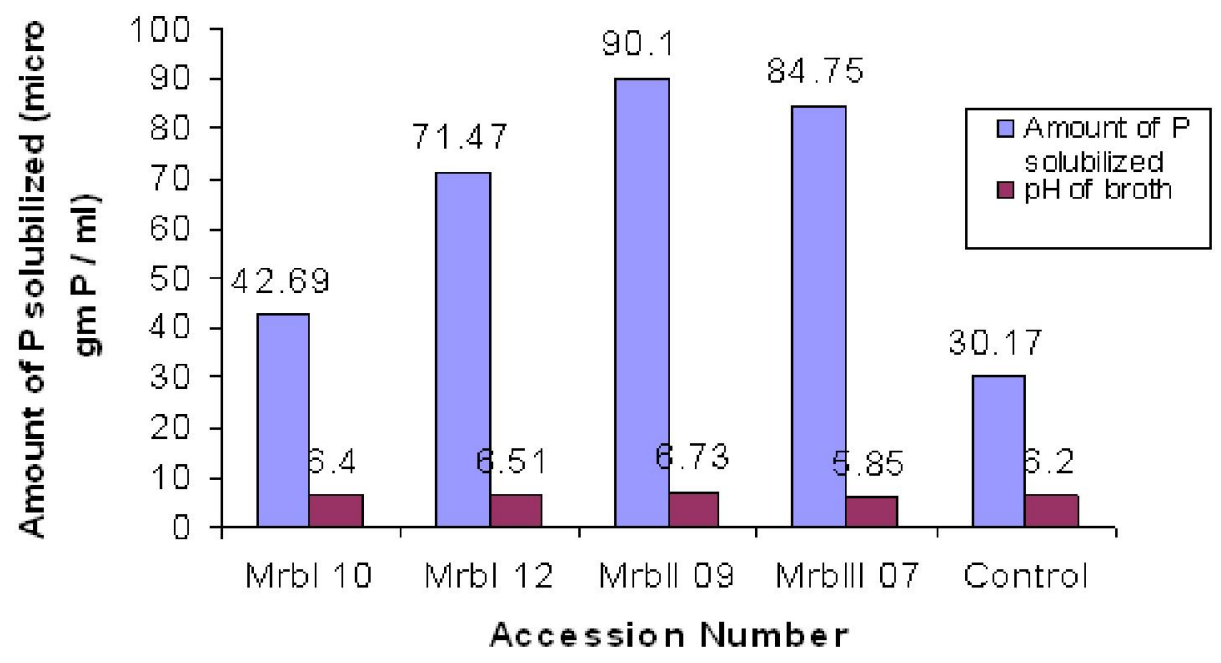

Fig. 1. A mount of $\mathrm{P}$-solubilized and $\mathrm{pH}$ after $7 \mathrm{~d}$ of incubation.

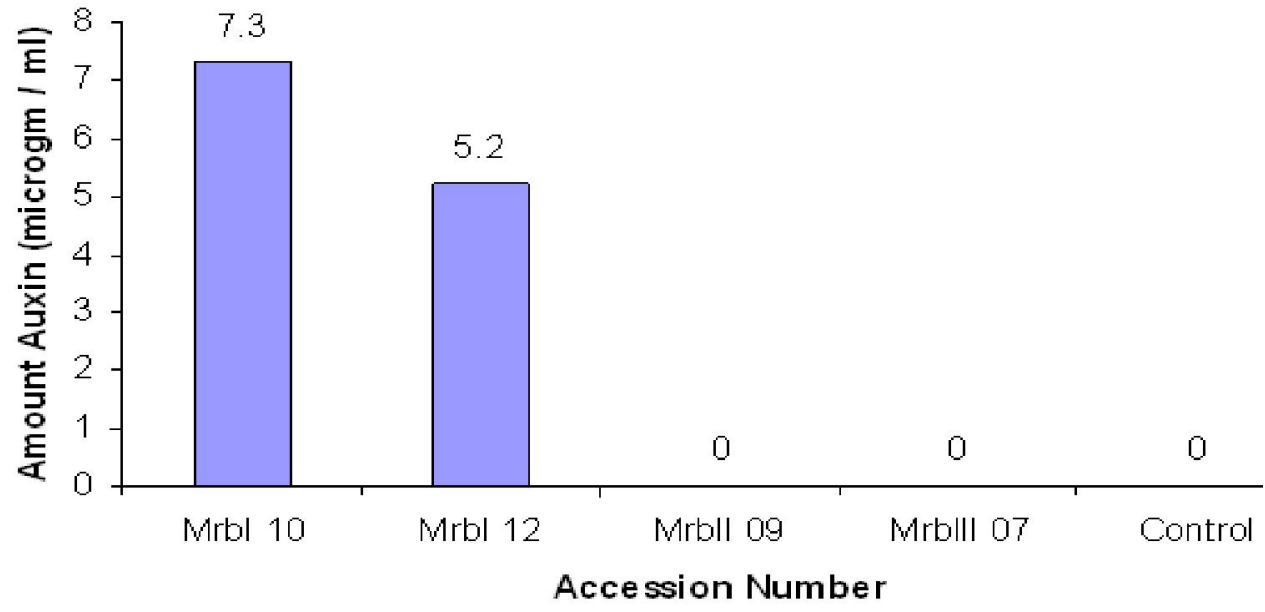

Fig. 2. Auxin / Auxin like substance production by P-solubilizing rhizobacterial isolates. 


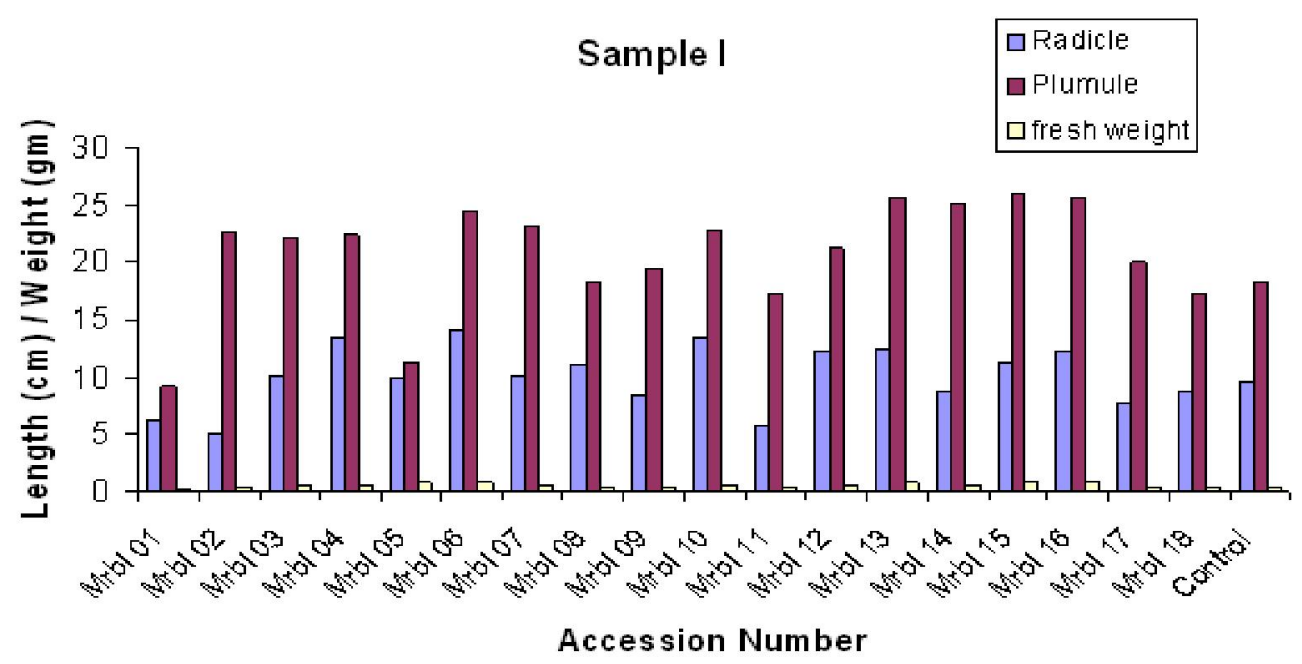

Fig. 3. Effect of rhizobacterial isolates on length of plumule, radicle and fresh weight.

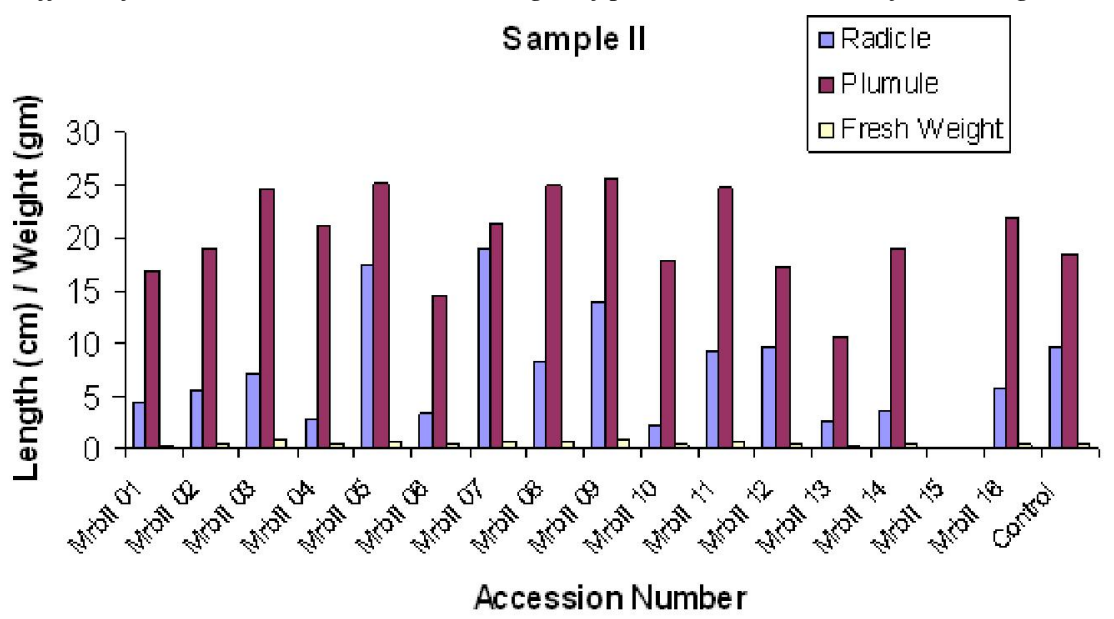

Fig. 4. Effect of rhizobacterial isolates on length of plumule, radicle and fresh weight.

with rhizobacterial isolates and placed on $0.7 \%$ water agar plates and incubated at $37 \pm 2{ }^{\circ} \mathrm{C}$. Most of the rhizobacterial isolates $(34.72 \%)$ increased length of plumule and radicle along with fresh weight. However $4.16 \%$ isolates have inhibited germination of seeds. (Figs. 3-6) Parmar and Dadarwal (1997) observed similar kind of effect on Chick pea seedlings, when tested with 35 Chick pea rhizospheric bacteria with chick pea seedling growth.

\section{DISCUSSION}

In present investigation out off 72 rhizobacterial isolates only four (5.55\%) isolates namely MrbI 10 and MrbI 12, MrbII 09 and MrbIV 07 were able to solubilize tri calcium phosphate (TCP) in the Pikovskaya broth, solubilizing phosphorus in considerably higher amount ranging from $42.69 \mu \mathrm{g} / \mathrm{ml}$ to $90.10 \mu \mathrm{g} / \mathrm{ml}$. However, their ability to solubilize inorganic phosphate could not be solely ascribed to acid production as the $\mathrm{pH}$ reduction was not high. Maximum phosphate solubilization was shown by MrbII 09 followed by MrbIII 07, MrbI 12 and MrbI 10. Kucey (1983) reported that P solubilizing bacteria made up $0.5 \%$ of the cultarable soil population.
The rhizosphere of mungbean harbours P-solubilizers, out of four selected PGPR two (50\%) namely MrbI 10 and MrbI 12 were found to produce IAA like substances in small amount i.e. $7.4 \mathrm{mg} / \mathrm{ml}$ and $5.2 \mathrm{mg} / \mathrm{ml}$. This is also evident by increase in radicle length of mung bean seedlings. Koh et al. (2007) also observed increased total length and biomass of tomato seedlings by IAA producing Rhodopseudomonas sp. However, rest of the two isolates (MrbII 9 and MrbIII 7) also increased length of radicle but were unable to produce detectable amount of IAA in vitro.

Total fifty eight 58 isolates (80.55\%) were able to fix nitrogen and they have exhibited variable response with seedling emergence, length of plumule and radicle and fresh weight. Md. Harunor et al. (2008) also reported presence of $34.60 \%$ nitrogen fixing rhizobacteria from one month old rice seedlings. In present investigation it was found that isolates MrbI 11, MrbI 18, MrbII 01, MrbII 06, MrbII 10, MrbII 13 and MrbIV 15 fixed nitrogen but decreased all growth parameters in water agar plates. Isolates MrbII 02, MrbIII 16 and MrbIV 18 were unable to fix nitrogen but inhibited the growth of seedlings, for 


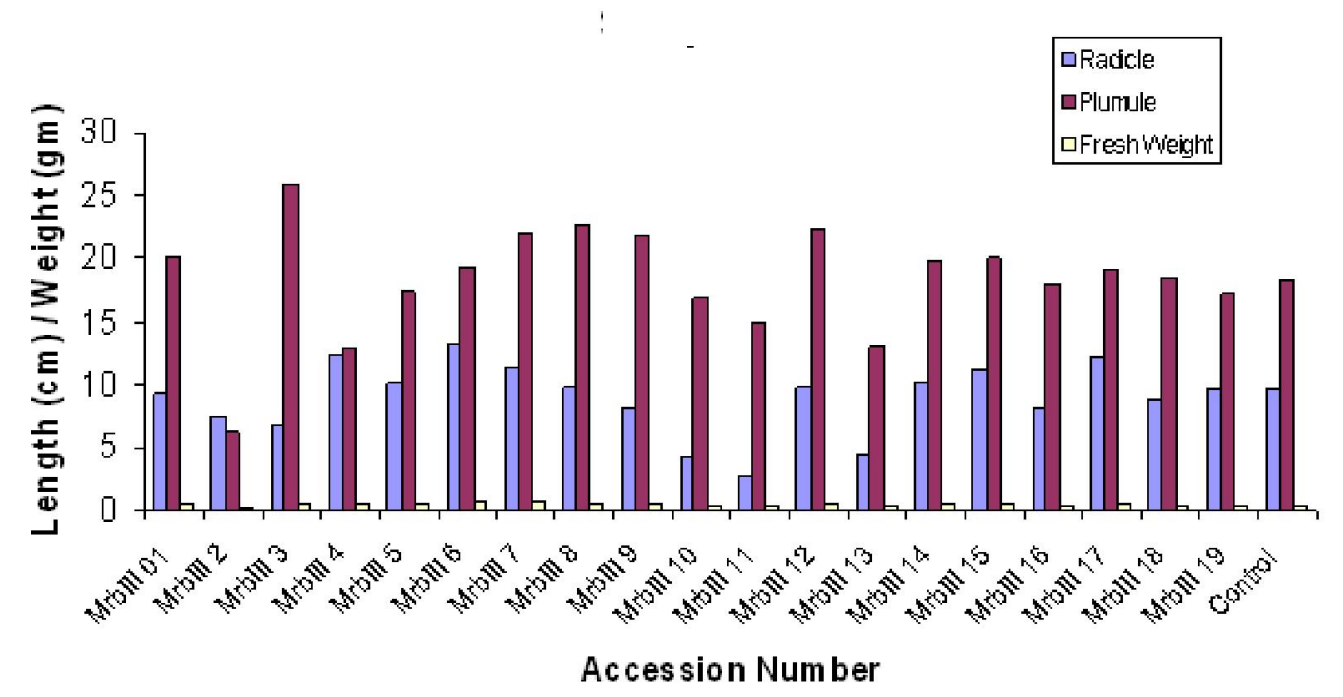

Fig. 5. Effect of rhizobacterial isolates on length of plumule, radicle and fresh weight.

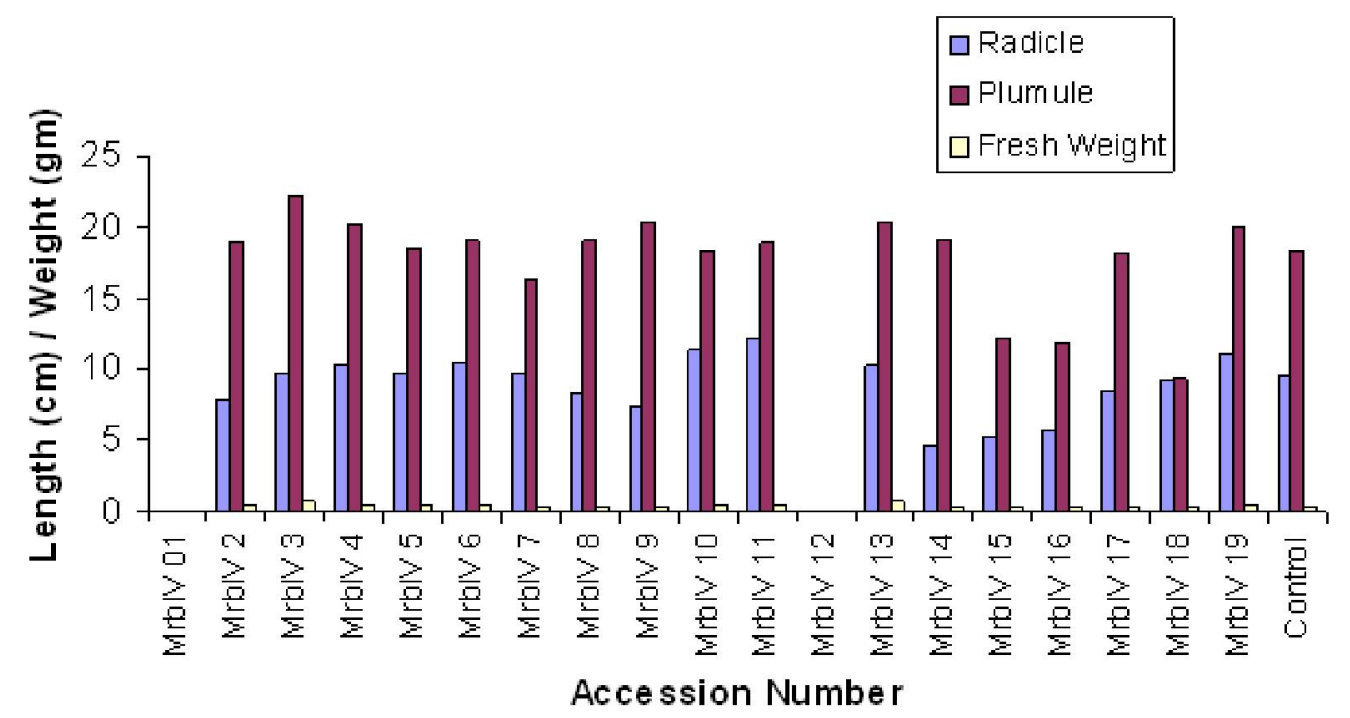

Fig. 6. Effect of rhizobacterial isolates on length of plumule, radicle and fresh weight.

rest of the isolates growth parameter could not be solely correlated to nitrogen fixation.

\section{Conclusion}

The present investigation revealed that the mung bean rhizosphere harbors plant growth promoting bacteria that help them to grow by fixing environmental nitrogen, solubilizing inorganic phosphate, producing auxin like substances and supporting growth of rhizobium.

\section{REFERENCES}

Fred, E. B., Baldwin I. L. and F. McCoy (1932). Root nodule bacteria and leguminous plants with supplement. U niv. Wis. Stud. Sci. No. 5, Madison.

Gerke, J. (1992). Phosphate, aluminum and iron in the soil solution of three different soils in relation to varying concentrations of citric acid. Zeitschrift Pflanzenernahr Bodenkunde, 155:339-343

Gordon, S. A. and Weber, R. P. (1951). Colorimetric estimation of indoleacetic acid. Plant Physiol., 26:192-195.

Illmer, P. and Schinner, F.(1992). Solubilization of inorganic phosphates by microorganisms isolated from forest soil. Soil Biol. Biochem., 24:389-395.

Jackson, M. L. (1967). In: Soil Chemical Analysis. Prentice Hall of India Pvt. Ltd., New Delhi.

King, E. O., Ward, M. K. and Raney, D. E. (1954), Two simple media for the demonstration of pyocyanin and fluorescein. J. Lab. Clin. M ed., 44: 301-307.

Koh, Rae-Hyun and Hong-gyu Song (2007). Effects of application of Rhodopseudomonas sp. on seed germination and growth of tomato under axenic conditions. J. M icrobiol. Biotechnol., 17 (11): 1805-1810.

Kucey, R. M. N. (1983). Effect of Penicillium bilaji on solubility and uptake of $\mathrm{P}$ and micronutrients from soil by wheat. Can. J. Soil. Sci., 63: 671-678.

Md. Harunor Rashid Khan, Md. Mohiuddin and M. Rahman. (2008). Enumeration, isolation and identification of Nitrogenfixing bacterial strains at seedling stage in rhizosphere of rice grown in non-calcareous grey flood plain soil of 
Bangladesh.J ournal of the F aculty of E nvironmental Science and Technology. 0 kayama U niver sity. 13: 97-10.

Parmar N. and Dadarwal K. R. (1997). Rhizobacteria from the rhizosphere and rhizoplane of chick pea (Cicer arietinum L.). Indian J . Microbiol., 37: 205-10

Pikovskaya, R. E. (1948). Mobilization of phosphorus in soil in connection with vital activity of some microbial species. Mikrobiologiya, 17: 362-70

Prasanna, A., Deepa,V., Murthy, P. B., Deecaraman, M., Sridhar, R. and Dhandapani,P. (2011). Insoluble phosphate solubilization by bacterial strains isolated from rice rhizosphere soils from Southern India. Int. J . Soil Sci., 6: 134-141.

Rodreguez, H. and R. Fraga, (1999). Phosphate solubilizing bacteria and their role in plant growth promotion. Biotechnol. Adv., 17:319-339.

Schwinghamer, E. A. (1971). Antagonism between strains of Rhizobium trifolii inculture. Soil. Biol. Biochem., 3: 355-363 Vincent J.M. (1970). A manual for the practical study of the root nodule bacteria. Blackwell Scientific Pub. Oxford and Edinburgh. pp 1-13.

Yin, R. (1988). Phosphate-solubilizing microbes in non-irrigated soils in china. Soils, 20: 243-246. 